\title{
Pseudopapillary and Macrofollicular Microscopic Growth Patterns in an Advanced Stage Ovarian Dysgerminoma: A Case Report
}

\author{
Fatemeh Nili ${ }^{1}$, Niusha Nobari ${ }^{1}$, Alireza Abdollahi ${ }^{2 *}$ \\ 1. Dept. of Pathology, Cancer Institute, Tehran University of Medical Sciences, Tehran, Iran \\ 2. Dept. of Pathology, Imam Hospital Complex, School of Medicine, Tehran University of Medical \\ Sciences, Tehran, Iran
}

\begin{tabular}{c} 
KEYWORDS \\
\hline Dysgerminoma \\
Microscopic Growth Pattern \\
Pseudopapillary \\
Macrofollicular \\
\hline
\end{tabular}

Article Info

Received 15 Sep 2016;

Accepted 26 Apr 2017;

Published Online 2017;

\begin{abstract}
Dysgerminoma is one of the two most common types of ovarian germ cell tumors. Providing accurate pathologic diagnosis and treatment planning, the prognosis is good even in advanced stages. Pathologic diagnosis is generally straightforward. In microscopic examination, the usual known growth patterns in tumor cells are solid, trabecular, insular and rarely pseudoglandular.

In this paper, we reported an advanced ovarian dysgerminoma with different microscopic patterns of growth, including pseudopapillary and macrofollicular structures, in an 18-year-old woman. The patient underwent staging laparotomy and is currently receiving chemotherapy.
\end{abstract}

Corresponding Author: Dr. Alireza Abdollahi, Professor of Pathology, Department of Pathology, Imam Hospital Complex, School of Medicine, Tehran University of Medical Sciences, Tehran, Iran. Telefax: 982166591317, Email: abdollahi_a@tums.ac.ir.

Copyright ( ) 2017, IRANIAN JOURNAL OF PATHOLOGY. This is an open-access article distributed under the terms of the Creative Commons Attributionnoncommercial 4.0 International License which permits copy and redistribute the material just in noncommercial usages, provided the original work is properly cited.

\section{Introduction}

The three major types of ovarian tumors are epithelial, sex cord and germ cell (1). Epithelial cell tumors represent the majority of all ovarian neoplasms (82\%) (1). Conversely, germ cell tumors (GCTs) are rare, comprising approximately $20 \%$ of all ovarian tumors, both benign and malignant ones $(1,2)$. Approximately $3-5 \%$ of ovarian GCTs are malignant (2). The most commonly occurring GCTs is dysgerminoma, which accounts for approximately $2 \%$ of all ovarian cancers (2). Extra-ovarian tumor spread of dysgerminomas often involves the retroperitoneal and pelvic lymph nodes; these tumors are highly susceptible to radiotherapy (3).

In addition, hematogenous spread may occur; common sites of involvement are lungs, liver and bones (3).

Dysgerminoma is one of two most common types of ovarian germ cell tumor (1-3). It has been reported in a wide range of seven months to seventy years, but most cases are young adults and less than twenty years (4). The known fact is that dysgerminomas account for two-thirds of the entire malignant ovarian neoplasms in women aged under 20. The Dysgerminomas' response to therapy has turned out to be good (4-6).

On gross examination, they are usually solid masses with lobulated homogenous cut surface. The foci of necrosis, hemorrhage and cystic degeneration may be present but suggest the possibility of other neoplastic germ cell elements $(6,7)$.

In microscopic examination, the monotonous populations of large polygonal round or oval cells with clear or slightly eosinophilic nuclei containing one or two eosinophilic nucleoli are seen $(3,7)$. Patterns of growth include solid, trabecular, insular, pseudoglandular and singly disposed cells that are intersected by fibrous septa with 
infiltration of inflammatory cells, predominantly lymphocytes $(6,8)$.

About two-thirds of dysgerminomas are in stage IA at the time of operation. Prognosis is excellent for this group of patients with more than $95 \%$ fiveyear survival (7-9). About 5-15\% of patients have bilateral ovarian involvement and few present lymph node metastases and/or peritoneal involvement. However, prognosis in these groups is well with $85 \%$ five-year survival after appropriate chemotherapy $(6,10)$.

We reported here a case of advanced ovarian dysgerminoma with unusual macroscopic appearance and different patterns of growth in microscopic examination.

\section{Case Report}

An 18-year-old female, single and nulligravid, referred to the Gynecology Department with complaint of abdominal pain, weight loss and ascites. Computed Topography of abdomen and pelvic showed solid mass measuring 130x120x78 $\mathrm{mm}$ with the origin of the left side of pelvis probably the left ovary, ascites and peritoneal vegetative seedings beneath the right diaphragm and both flanks in favor of omental cake, as well as two 52 and $48 \mathrm{~mm}$ masses in cul-de-sac (blumer shelf).

Analyzed tumor markers show an increase in the serum level of Cancer Antigen 125 (CA125), Lactate dehydrogenase (LDH) and Human Epididymis Protein 4 (HE4), but normal level of Carcinoembryonic antigen (CEA), Alphafetoprotein (AFP), Cancer Antigen 19-9 (CA 19-9) and Human chorionic gonadotropin ( $\beta \mathrm{HCG})$. The patient underwent laparotomy to resect the left ovarian mass with surface involvement, adhesion to pelvic side wall and disseminated omental involvement. Left salpingo-oophorectomy, omentectomy and appendectomy were performed. The excised mass was sent to the pathology department. It was a 170-gr lobulated and perforated ovarian mass measuring $12 \times 11 \times 6.5 \mathrm{~cm}$. Cut sections showed non-homogeneous tanbrownish surfaces with papillary projections in some foci. Microscopic examination exhibited cellular neoplasm composed of large polyhedral cells with clear cytoplasm and large angulated nuclei with 1-3 prominent eosinophilic nucleoli. Neoplastic cells arranged in pseudopapillary, solid nests and macrofollicular structures. Delicate fibroconnective stroma with scattered infiltration of small lymphocytes in some foci were also detected (Figure 1).

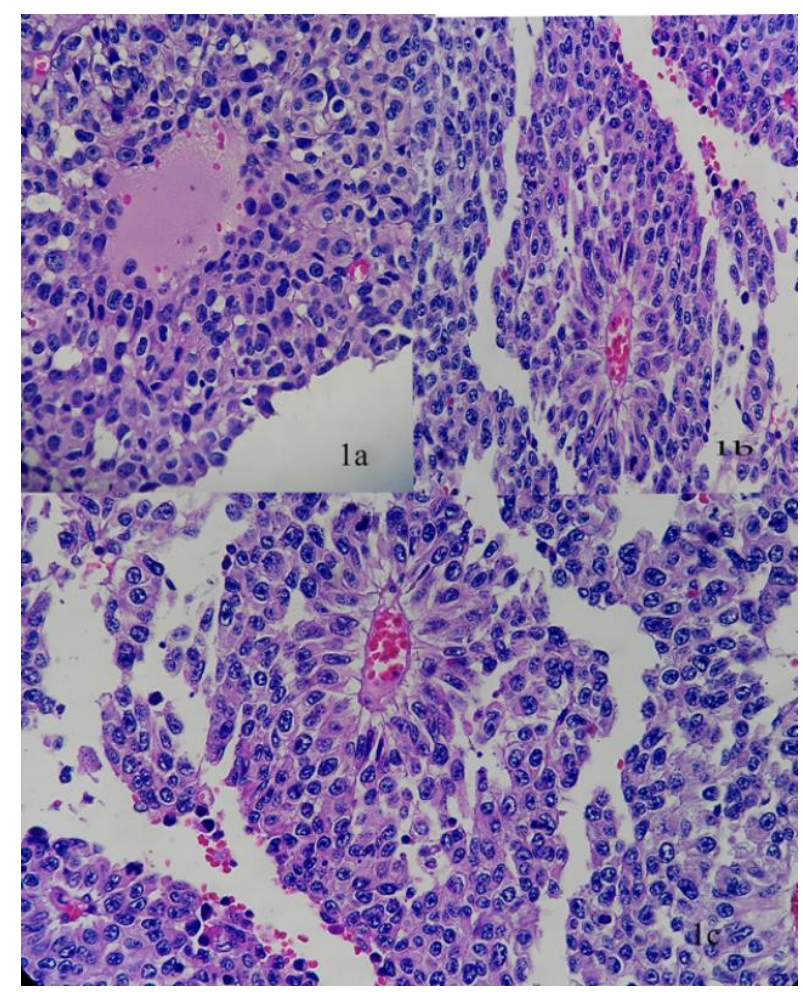

Fig 1 Frond-like structures with a vascular core making pseudopapillary pattern of growth Follicle-like spaces with variability in size and content, Distinct cytologic features; polygonal cells with clear cytoplasm and round to angulated nuclei with prominent 1-2 nucleoli.

Immunohistochemical staining had positive findings for CD117, CK AE1/AE3 and PLAP and negative for Inhibin, Calretinin, AFP and CD30 (Figure 2a, 2b, 2c) indicating the diagnosis of dysgerminoma. Chemotherapy was initiated based on microscopic diagnosis, including etoposide, cisplatin and bleomycin. 


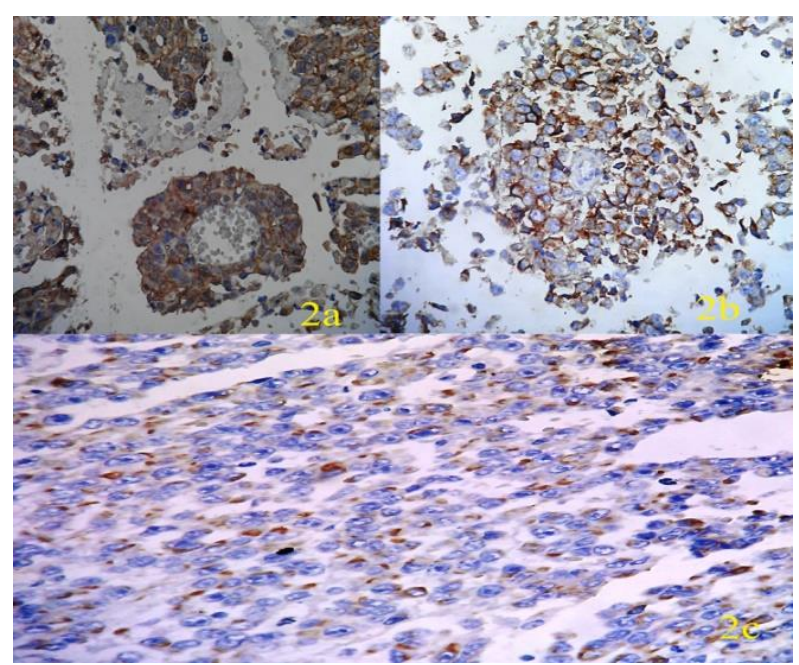

Fig 2a,2b,2c. Immunoreactivity with CD117, PLAP and $\mathrm{CK}$ AE1/AE3

Despite the advanced stage of the tumor, peritoneal involvement, surgical complications such as fever, intra-abdominal abscess formation and pleural effusion, the general status of the patient was good in her fourth course of chemotherapy owing to immediate initiation of proper treatment.

\section{Discussion}

Dysgerminoma accounts for $1-2 \%$ of all primary ovarian tumors and is one of the most common types of malignant germ cell neoplasms $(3,11)$.

It is highly chemosensitive and responds well to a combination of Cisplatin, Bleomycin and Etoposide (BEP) (12). Due to good prognosis, distinction from other types of ovarian neoplasms is of important value. In general, based on the characteristic morphologic features, the diagnosis is straightforward. However, it may exhibit different patterns of growth which may cause difficulty to an accurate diagnosis $(11,13)$. This case needs reporting due to its unusual morphological pattern.

Embryonal carcinoma, yolk sac tumor, clear cell carcinoma, malignant lymphoma, sex cord stromal tumors including sertoli leydig and steroid cell tumor are the main differential diagnoses of dysgerminoma on histologic examination $(5,10,14)$. Distinct cytologic features, lobulated architecture with lymphocytes in the interlobular fibrous septa, and immunohistochemistry are helpful for an accurate diagnosis (5). Pseudoglandular, trabecular and solid tubular microscopic architectures have led to a misdiagnosis of sertoli cell tumors $(11,15)$.

Macrofollicule defined as the presence of large, relatively uniform follicles resembling follicle cyst is a typical structure in juvenile granulosa cell tumor, small cell carcinoma or metastatic melanoma $(12,13,16)$. This structure was seen frequently in the microscopic examination of our case, leading to misdiagnosis as granulosa cell tumor by some of our colleagues. Pseudopapillary structures in the reported case also mimicked transitional cell carcinoma as another important differential diagnosis. Typical cytologic characteristics and immunoreactivity with PLAP and CD117 as well as negative reaction with inhibin and calretinin helped us with the accurate diagnosis.

Pure dysgerminoma is a rapidly growing malignant tumor. Despite the fact, metastatic spread in the early stages is not common.$^{5}$ It has been suggested that highly cellular tumors with a small amount of stroma and lymphocytic infiltration as well as marked atypia and high mitotic activity tend to be more aggressive (12). However, there is still no good evidence for predicting the behavior of neoplasm by its histologic appearance $(8,17)$. In our patient, a cellular tumor with little fibrous stroma and inflammatory cell infiltrate together with unusual microscopic growth patterns and disseminated peritoneal involvement were seen. These clinical and morphological findings may be either coincidental or in relationship with each other. There are not enough documents for this distinction. More investigations are needed.

Radiologic surveys are instrumental in the diagnosis of dysgerminoma. The primary aim of radiologic survey is differentiation of malignant tumors from benign ones, rather than determination of histologic subtype (17).

\section{Conclusion}

Although the morphologic diagnosis of dysgerminoma is generally simple and not complicated, there are unusual microscopic 
findings including pseudopapillary and macrofollicular structures, which may cause difficulty to an accurate diagnosis. Characteristic cytologic features and immunohistochemistry are useful for a correct recognition.

\section{Acknowledgment}

The authors declared no conflict of interests.

\section{Declaration of Conflicting Interests}

The author(s) declared no potential conflict of interests regarding the research, authorship and/or publication of this article.

\section{Funding}

The author(s) received no financial support for the research, authorship and/or publication of this article.

\section{Ethical issue}

The authors wrote the case report after obtaining an informed consent from the patient.

\section{References}

1. Smith HO, Berwick M, Verschraegen CF, Wiggins C, Lansing L, Muller CY, et al. Incidence and survival rates forfemale malignant germ cell tumors. Obstet Gynecol 2006; 107(5):1075-85.

2. Lee KH, Lee IH, Kim BG, Nam JH, Kim WK, Kang SB, et al. Clinicopathologic characteristics of malignant germ cell tumors in the ovaries of Korean women: a Korean Gynecologic Oncology Group Study. Int J Gynecol Cancer 2009;19(1):84-7.

3. Mueller CW, Topkins P, Lapp WA. Dysgerminoma of the ovary. An analysis of 427 cases.Am J Obstet Gynecol 1950; 60:153.

4. Santesson L. Clinical and pathological survey of ovarian tumours treated at the Radiumhemmet. 1. Dysgerminoma. Acta Radiol (Stockh) 1947; 28:643.

5. Jiang JF, Xue W, Deng Y, Tian QJ, Sun AJ. Gonadal malignancy in 202 female patients with disorders of sex development containing $\mathrm{Y}$ - chromosome material. Gynecol Endocrinol 2015 ; 26:1-4.

6. Vale-Fernandes E, Rodrigues F, Monteiro $\mathrm{C}$, Serrano P. Pelvic mass in a young woman with a background of ovarian dysgerminoma: differential diagnosis. BMJ Case Rep 2015; 17; 2015.

7. Asadourian LA, Taylor HB. Dysgerminoma. An analysis of 105 cases. Obstet Gynecol 1969; 33:370.

8. Bjorkholm E, Lundell M, Gyftodimos A, Silversward C.Dysgerminoma. The Radiumhemmet series 1927-1984. Cancer (Phila).1990; 65:38.

9. Gershenson DM . Update on malignant ovarian germ cell tumors. Cancer (Phila).1993; $71: 1581$.

10. Kamal NM, Khan U, Mirza S, Mazoun K, Mirza FM, Jundi M. Ovarian dysgerminoma with normal serum tumour markers presenting in a child with precocious puberty. J Cancer Res Ther 2015; 11(3):661.

11. Arafah MA, Tulbah AM, Al-Husaini H, AlSabban M, Al-Shankiti H, Al-Badawi IA. Extrauterine epithelioid trophoblastic tumor arising in the ovary with multiple metastases: a case report. Int J Surg Pathol 2015; 23(4):339-44.

12. Arafah MA, Tulbah AM, Al-Husaini H, Al-Sabban M, Al-Shankiti H, Al-Badawi IA. Extrauterine epithelioid trophoblastic tumor arising in the ovary with multiple metastases: a case report. Int J Surg Pathol 2015; 23(4):339-44.

13. Atkin NB. High chromosome numbers of seminomata and malignant teratomata of the testis: a review of data on 103 tumors. Br J Cancer 1973; 28:275.

14. Shintaku M, Dohi M, Yamamoto Y, Nagai A, Higuchi T. Ovarian clear cell carcinoma with plasma cell-rich inflammatory stroma: Cytological Findings of a Case. Diagn Cytopathol 2016; 8.

15. Hannan A, Malik MA, Fasih S, Badar F, Siddiqui N. Malignant Ovarian germ cell tumors at a tertiary care srtting in pakistan. J Ayub Med Coll Abbottabad 2015; 27(3):624-7. 
16. Kamal NM, Khan U, Mirza S, Mazoun K, Mirza FM, Jundi M. Ovarian dysgerminoma with normal serum tumour markers presenting in a child with precocious puberty. J Cancer Res Ther 2015; 11(3):661.
17. Kato N, Kurotaki H, Uchigasaki S, Fukase M, Kurose A. Ovarian clear cell carcinoma with plasma cell-rich inflammatory stroma: a clear cell carcinoma subgroup with distinct clinicopathological features. Histopathology 2016; 68(4):588-95.

\section{How to Cite This Article}

Nili F, Noubari N, Abdollahi A. Pseudopapillary and Macrofollicular Microscopic Growth Patterns in an Advanced Stage Ovarian Dysgerminoma: A Case Report. Iran J Pathol. 2018; 13(1): 94-98. 